\title{
Explorando desafios pedagógicos digitais no ensino profissional durante a pandemia da COVID-19
}

Ana Nobre ${ }^{1}$

\section{RESUMO}

Em todo o mundo, a pandemia causou mudanças substanciais nos mais variados domínios e o setor da Educação não foi exceção. A situação atual sem precedentes exigiu uma transição rápida do ensino-aprendizagem presencial para uma Educação Virtual. 0 artigo explora os desafios enfrentados por docentes do Ensino Profissional durante a pandemia. Neste estudo quantitativo, foi partilhado um questionário com 129 professores que lecionaram em 5 centros profissionalizantes. Os resultados revelaram que durante o Ensino on-line surgiram obstáculos diversos, como a falta de formação e experiência, a falta de conectividade com a internet, a falta de eletricidade, o medo das aulas on-line, o plágio durante as avaliações digitais, a falta de comunicação não verbal etc.

Palavras-chave: Ensino-aprendizagem digital. Pandemia COVID-19. Ensino Profissional. Tecnologia digital. 


\section{Exploring digital pedagogical challenges in vocational education during COVID-19 pandemic}

\section{ABSTRACT}

Across the entire world, the pandemic has caused substantial changes in all its domains and the education sector is no exception. The current unprecedented situation called for a rapid transition from face-to-face teaching to virtual education. The paper explores the challenges faced by teachers in vocational education during the pandemic. In this quantitative study, a questionnaire was shared with 129 teachers who taught at 5 professional education centers. The results revealed that, during online teaching, diverse challenges arose, such as lack of training and experience, internet connectivity, lack of electricity, fear of online classes, plagiarism during digital assessments, lack of non-verbal communication, etc.

Keywords: Digital teaching-learning. COVID-19 Pandemic. Vocational Education. Digital technology. 


\section{INTRODUÇÃO}

Em 2020, a pandemia da COVID-19 transformou todas as esferas da vida: médica, financeira, indústria de negócios e alimentícia, moda, educação etc. O setor da Educação foi tremendamente afetado por abranger uma ampla gama de estudantes e professores da população em geral. Ao refletir-se sobre os efeitos da pandemia, em particular no domínio educacional, notamos que o crescimento intelectual por meio da partilha de ideias e comunicação interpessoal entre adultos sofreu reveses. Assim, o distanciamento social tem causado muitos danos no desenvolvimento da intelectualidade e criatividade de adultos nas organizações acadêmicas (MURPHY, 2020).

Este artigo incide sobre a transformação do ensino-aprendizagem em tempo de pandemia. Desse modo, partilha-se os desafios pedagógicos dos docentes na formação profissional. A problemática que se verifica de forma empírica é que no primeiro ano da COVID-19 os docentes tiveram que se adaptar às mudanças em um cenário inédito. Foi necessário muito empenho e produção de um planeamento estratégico: trabalhar em casa - teletrabalho -, horários de trabalho flexíveis, fechar escolas, universidades e demais instituições educacionais. Essa situação obrigou todas as instituições a dar continuidade ao processo didático por intermédio de plataformas digitais. Os sistemas de ensino não estavam preparados para iniciar a instrução na modalidade de e-learning em caráter de emergência e praticar o ensino-aprendizagem digital (NOBRE et al. 2019). Foi necessário preparar docentes e discentes, efetuar uma escolha - quais plataformas digitais utilizar, por exemplo -, adaptar e flexibilizar o ensino-aprendizagem, pois o contexto de ensino e aprendizagem digital precisa de planeamento (BOZKURT; SHARMA, 2020). Esse cenário trouxe muitos problemas a professores e estudantes. Os docentes foram confrontados com a responsabilidade de formar a próxima geração, a qual deverá enfrentar e competir com o fenômeno digital em que tudo será dominado por robôs e máquinas gigantes (NOBRE, 2021). Não estamos a envolver os estudantes no estudo digital com a ajuda das plataformas digitais, estamos, na verdade, a preparar uma geração digital que revolucionará o mundo nos próximos anos.

\section{A TRANSFORMAÇÃO DO ENSINO-APRENDIZAGEM NO CONTEXTO DA PANDEMIA DA COVID-19}

$\mathrm{Na}$ atual conjuntura da pandemia do novo coronavírus, o sistema de ensino em todo o mundo passou por mudanças e ainda é confrontado constantemente a reajustes. Houve uma transferência da interação humana para a interação digital, na qual tudo depende do ambiente virtual. A maioria dos docentes não estavam preparados para esse sistema de ensinoaprendizagem digital. Foram efetuadas pesquisas para abordar as dificuldades e os problemas enfrentados pelos professores nesse domínio durante a pandemia no contexto de Portugal. Nesse cenário pandêmico, muitos caminhos surgiram. Para o bom funcionamento do processo de ensino e aprendizagem, os docentes e discentes percorreram esses trilhos. Este estudo é restrito 
a docentes, formadores de diversas áreas do Ensino Profissional - incluindo línguas estrangeiras -, de cinco sedes de formação no centro, norte e sul de Portugal. Procura-se analisar a passagem do Ensino Profissional na modalidade presencial para a modalidade de ensino-aprendizagem digital durante o confinamento causado pela pandemia no segundo semestre de 2020.

\subsection{Os Desafios do Digital}

O estudo fornece uma visão geral do conceito de ensino na modalidade de e-learning e dos desafios conforme a visão de outros pesquisadores. O e-learning é, na verdade, uma aprendizagem constante (NOBRE, 2020) da utilização das tecnologias digitais e da Internet. A aprendizagem digital é a aplicação de métodos de aprendizagem por meio da Tecnologia Digital da Informação e Comunicação (TDIC). Da confluência dos desafios econômicos e sociais da globalização reconfigurados pela tecnologia (NOBRE; MOURAZ, 2020) resulta a aprendizagem digital, ou seja, a aplicação de métodos de aprendizagem por meio das TDIC que interconectam estudantes, professores, intelectuais, críticos e colegas profissionais de diversas organizações (ABERNATHY; THORNBURG, 2020). A Política de e-learning (2007-2010) da Universidade de Liverpool refere que tal método envolve o uso da tecnologia digital no processo de aprendizagem-ensino e criação de novos materiais de aprendizagem através de plataformas digitais (SIDDIQUEI; KHALID, 2017).

Assareh e Bidokht (2011) definem o e-learning como uma espécie de plataforma de ensino on-line em que o processo de ensino é realizado por um navegador web, ou através de um CDROM ou DVD; o uso da internet é fundamental nessa modalidade. Sun e Chen (2016) ressaltaram que é crucial formar professores para o ensino-aprendizagem digital. O corpo docente deve saber como usar as plataformas on-line e tecnologias do mundo virtual. O desenvolvimento profissional concentra-se no ponto de como desenvolver estratégias de ensino-aprendizagem utilizando tais tecnologias.

Surgiram várias brechas no sistema baseado na aprendizagem digital. 0 acesso à tecnologia na Educação é uma das mais importantes "fendas". Antes de iniciar o ensinoaprendizagem digital, o professor deve aprender a utilizar as tecnologias digitais, para que não tenha nenhuma dificuldade nesse sentido. Islam, Beer e Slack (2015) apresenta uma perspectiva diferente; o ensino afeta a aprendizagem dos estudantes, mas, também, afeta a sua cultura. A aprendizagem cultural dos estudantes é perturbada pelo ensino-aprendizagem digital. Estudantes que falam línguas diferentes ou que habitam em regiões muito distantes não respondem da mesma maneira às perguntas e tarefas dos professores em plataformas de elearning. Da mesma forma, Tereseviciene et al. (2020) sugeriram que o corpo docente deveria ter formação digital para superar o ensino-aprendizagem digital. Os docentes necessitam ter formações sobre a utilização dessas tecnologias, para saberem integrá-las ao ensinoaprendizagem seja o presencial ou o virtual. A maioria dos professores não tem formação no uso de tecnologia digital (BAXTER; CALLAGHAN; MCAVOY, 2018).

$O$ ensino-aprendizagem digital requer um entendimento por parte dos professores de como os estudantes aprendem e estudam por meio das plataformas. Esse conhecimento ajudaria os professores a planear, estruturar programas, elaborar planos de aula e planificar estratégias diversificadas. Assim, as plataformas digitais e os procedimentos de e-learning representam 
desafios e ameaças para estudantes e professores em diferentes graus. É importante que os professores sejam capazes de lidar com diferentes questões durante o processo de ensinoaprendizagem digital: lentidão da internet, instrumentos digitais adequados - computador, tablet - etc.

Os utilizadores de sistemas de e-learning enfrentam dificuldades em gerir o seu tempo (ISLAM; BEER; SLACK, 2015). Para além de outras questões, a gestão e o investimento de tempo são situações igualmente enfrentadas pelos professores durante esse cenário de ensino aprendizagem digital. A frequência das perguntas dos estudantes e as respostas esperadas no decorrer das sessões síncronas; as reuniões entre os educadores; as reuniões administrativas com os professores; além de outras reuniões de monitoramento representam um problema de consumo de tempo para os professores (GRABINSKI et al. 2020).

No domínio do uso da tecnologia, os materiais digitais para o ensino-aprendizagem digital apresentam contratempos diferentes; problemas de download de arquivos, problemas de instalação, problemas de login, problemas com reprodução de áudio e vídeo e muitos outros (MAZZARDO; NOBRE; MALLMANN, 2019). Dhawan (2020) falou sobre outros aspectos, como a frequência com que os estudantes se aborrecem nesse sistema de aprendizagem e a regularidade em que o material é apenas teórico, não deixando espaço para os estudantes se divertirem e se motivarem.

Os métodos de avaliação precisam ser revistos e adaptados quando se fala de ensinoaprendizagem digital. As formas de avaliação são vigiadas por meio de métodos síncronos no elearning e esses métodos afetam o empenho positivo dos estudantes (RODDY et al. 2017).

Para Dei (2019) o ensino-aprendizagem digital exige uma competência técnica por parte dos docentes, pois envolve muitas ferramentas. Segundo esse autor, os modos de comunicação também diferem na modalidade on-line, porque a comunicação, a discussão entre pares e o feedback são praticados e realizados por intermédio das salas virtuais. Ainda assim, os professores não têm apenas contrariedades técnicas, algumas são psicológicas: ansiedade pelo uso da tecnologia; sensação de estar fora da zona de conforto; desigualdade na avaliação trabalhos em grupo -; dificuldade na interação entre pares em apresentações eficazes etc (CHAUDHARY; SHAHZADI; MAHMOOD, 2019). Os docentes também enfrentam alguns problemas psíquicos que são fatores externos e estão ligados ao seu bem-estar e saúde física, como o uso extensivo da voz, dores de ouvido resultantes da utilização de auriculares e visão cada vez mais fraca.

Inicialmente, as aulas on-line nos cinco centros de formação não alcançaram o sucesso esperado. Os motivos foram a falta de formação e de planeamento estratégico, pois os professores tiveram de usar plataformas on-line, como Moodle, Zoom e Meet, mas não foram preparados para a utilização dessas tecnologias.

\subsection{Metodologia}

Sendo o objeto deste estudo o fenômeno educativo, a presente pesquisa foi conduzida por meio de uma abordagem qualitativa que, na essência, passa pela reflexão e interpretação da realidade observada e vivida. Dentre os caminhos da pesquisa qualitativa, buscou-se o estudo de 
caso como desenho investigativo, pois entende-se que o ensino-aprendizagem é um caso pertencente ao universo da Educação.

Conforme Gil (2019), o estudo de caso pode ser definido como exaustivo, profundo e extenso, de uma ou de poucas unidades empiricamente verificáveis, o que permite um conhecimento amplo e detalhado. Segundo Leão (2017), o estudo de caso como estratégia de investigação é abordado por vários autores, para os quais um caso pode ser algo bem definido ou concreto, como um indivíduo, um grupo ou uma organização; mas também pode ser algo menos delineado ou definido num plano mais abstrato, como decisões, programas, processos de implementação ou mudanças organizacionais. De acordo com Yin (2009), um estudo de caso é uma investigação empírica que observa um acontecimento contemporâneo dentro do seu contexto da vida real, especialmente quando os limites entre o fenômeno e o contexto não estão claramente definidos. Assim, o estudo de caso é pertinente quando se analisa os fatos nas suas condições contextuais.

\subsection{Participantes e Amostragem}

A participação no estudo foi constituída por 129 docentes que lecionaram on-line no segundo semestre de 2020 em 5 centros de Ensino Profissional durante a pandemia da COVID-19. Os participantes assinaram o termo de consentimento e colaboraram de forma voluntária para a pesquisa.

\subsection{Inquérito por Questionário}

Uma das técnicas de recolha de dados é a de inquérito por questionário. McLeod (2018) resume as características dessa técnica em barata, rápida e eficiente, pois são obtidas grandes quantidades de informações, além da possibilidade de ser administrada através de vários meios - por telefone, computador e de modo presencial. Apesar disso, os questionários também apresentam alguns problemas que devem ser levados em consideração, como a possibilidade dos respondentes mentirem.

As perguntas podem ser abertas ou fechadas, sendo comum conter questões de ambos os tipos a fim de proporcionar a recolha de dados quantitativos e qualitativos. A construção de questões fechadas recorre a dados nominais - quando é possível categorizar as respostas - e a dados ordinais, normalmente por meio da apresentação de escalas contínuas de classificação, as quais permitem medir forças, atitudes ou emoções.

Os questionários de respostas fechadas apresentam diversas vantagens como economicidade na sua aplicação, o que permite recolher grandes quantidades de dados juntos de grandes amostras de população em análise, obtendo assim dados mais representativos; as respostas podem ser facilmente convertidas em dados quantitativos de forma a possibilitar uma análise estatística; as perguntas estão normalizadas, ou seja, são apresentadas do mesmo modo a todos os respondentes. Isso permite que o questionário possa ser reaplicado e testado acerca da sua confiabilidade. 
O desenho de um questionário é um aspecto crítico para o sucesso de uma investigação, sendo necessário levar em conta um conjunto de fatores para a construção de um inquérito de qualidade.

O supracitado autor apresenta alguns fatores para a elaboração de bons questionários como: objetividade - o investigador deve garantir que todas as questões vão ao encontro dos objetivos de investigação; dimensão - questionários mais longos obtêm menos respostas, por isso deve-se evitar a construção de questionários muito longos. As questões devem ser curtas, claras, objetivas, eliminando-se itens desnecessários; teste piloto - deve ser realizado um pequeno teste prático para garantir que as questões sejam bem entendidas e obtenham feedback relativo ao desenho do questionário; organização das questões - as questões devem ser apresentadas numa sequência lógica, das mais genéricas para as mais específicas. $O$ investigador deve também garantir que as respostas não sejam influenciadas por questões anteriores; terminologia - a linguagem do questionário deve ser adequada ao vocabulário do grupo em estudo, devendo-se evitar a utilização de jargões técnicos; apresentação - o questionário deve ter uma aparência profissional, com instruções claras e concisas.

Marconi e Lakatos (2003) referem à etapa de pré-teste, isto é, após o desenho do questionário o mesmo deve ser testado junto de uma amostra reduzida da população. Essa etapa é importante, pois possibilita a identificação de falhas e oportunidades de melhoria no desenho do questionário. Por isso, para a validação do questionário foi realizado um estudo piloto.

O questionário foi disseminado entre 10 formadores da instituição de formação profissional, revisto e aprimorado após obter o feedback dos participantes envolvidos no estudo piloto. Utilizou-se o teste Alpha Cronbach para verificação da consistência interna do inquérito, encontrando o valor de 0,75 , considerado suficiente para cumprir os objetivos da pesquisa.

O questionário final teve como objetivo recolher as opiniões dos docentes durante a pandemia, incluindo os seus problemas gerais, desafios pedagógicos, problemas durante a formação, problemas sobre a avaliação e feedback geral.

\section{ANÁLISE DE DADOS E DISCUSSÃO}

Usando o Google Formulários, foi desenvolvido um questionário on-line como instrumento para essa investigação e enviado aos participantes por meio de diferentes plataformas digitais, como WhatsApp e e-mails. Esse questionário incluiu escolha múltipla, escala Likert e questões abertas; foi categorizado em 6 seções relacionadas com problemas enfrentados pelo professor durante a formação e docência digital. A primeira seção foi composta por cinco perguntas com base nas características dos participantes. A segunda agregou quatro perguntas sobre os problemas gerais dos partícipes relacionados com o Ensino Profissional on-line. A terceira seção envolveu questões relativas aos problemas durante o ensino-aprendizagem digital. Com seis perguntas, a quarta seção procurou saber a atitude dos estudantes durante o ensinoaprendizagem digital. A quinta abrangeu questionamentos sobre os métodos de avaliação questionários e tarefas - na formação digital. Por fim, a sexta seção abarcou quatro perguntas sobre o feedback geral dos participantes. 0 questionário demorava cerca de 10 a 15 minutos para ser concluído. Os dados foram coletados entre setembro e novembro de 2020. 


\subsection{Resultados}

Para a investigação, foram recolhidos dados quantitativos resultantes dos inquéritos por questionário.

Dos 129 inquiridos, constaram 108 do sexo masculino e apenas 21 do sexo feminino.

O gráfico 1 revela que pouco mais da metade dos formadores tinha entre 0 a 4 anos de experiência de Ensino Profissional; 42 tinham entre 5 a 9 anos; nenhum deles tinha entre 10 e 14 anos; e 18 possuíam mais de 15 anos de experiência docente. Um número notável de professores não tinha experiência de ensino-aprendizagem digital - Ensino on-line - antes da pandemia. Um total de 92 educadores relatou possuir um nível moderado no uso da tecnologia digital; 5 disseram ter um nível baixo; e 32 responderam que possuíam um grande conhecimento das tecnologias digitais.

\section{Gráfico 1 - : Caracterização dos participantes (N=129)}

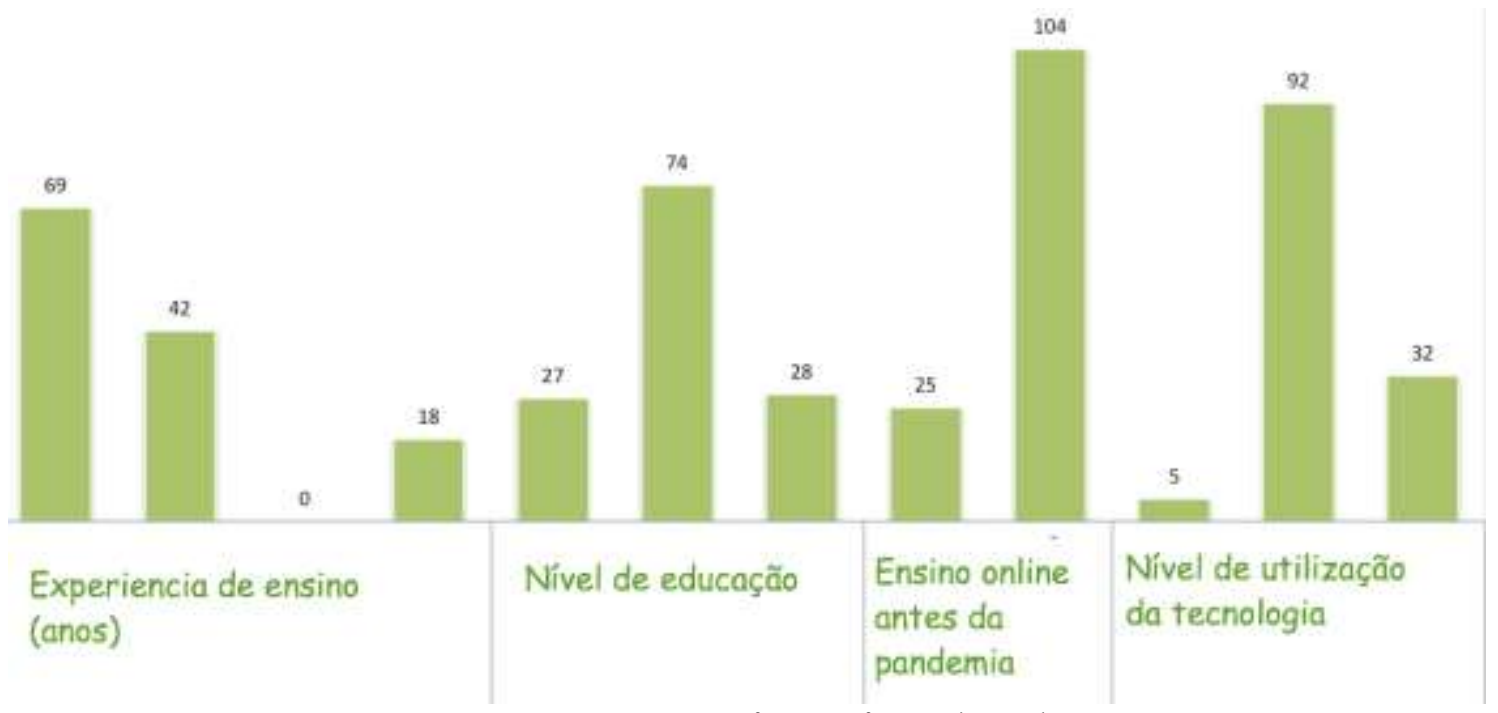

Fonte: Elaborado pelos autores com base na pesquisa realizada (2021).

O gráfico 2 demonstra os resultados dos respondentes sobre os problemas gerais que enfrentaram durante a formação on-line.

Embora um número notável de inquiridos tenha relatado que receberam formação antes de iniciar o ensino-aprendizagem digital - item 2.1 -, a maioria dos respondentes discordaram. Da mesma forma, 67 relataram ter medo e sentir ansiedade quando lecionam na modalidade de e-learning - item 2.3. Por fim, um número significativo concorda que desenvolveu uma certa "expertise" no ensino-aprendizagem digital - item 2.4 - durante os primeiros meses da pandemia. 


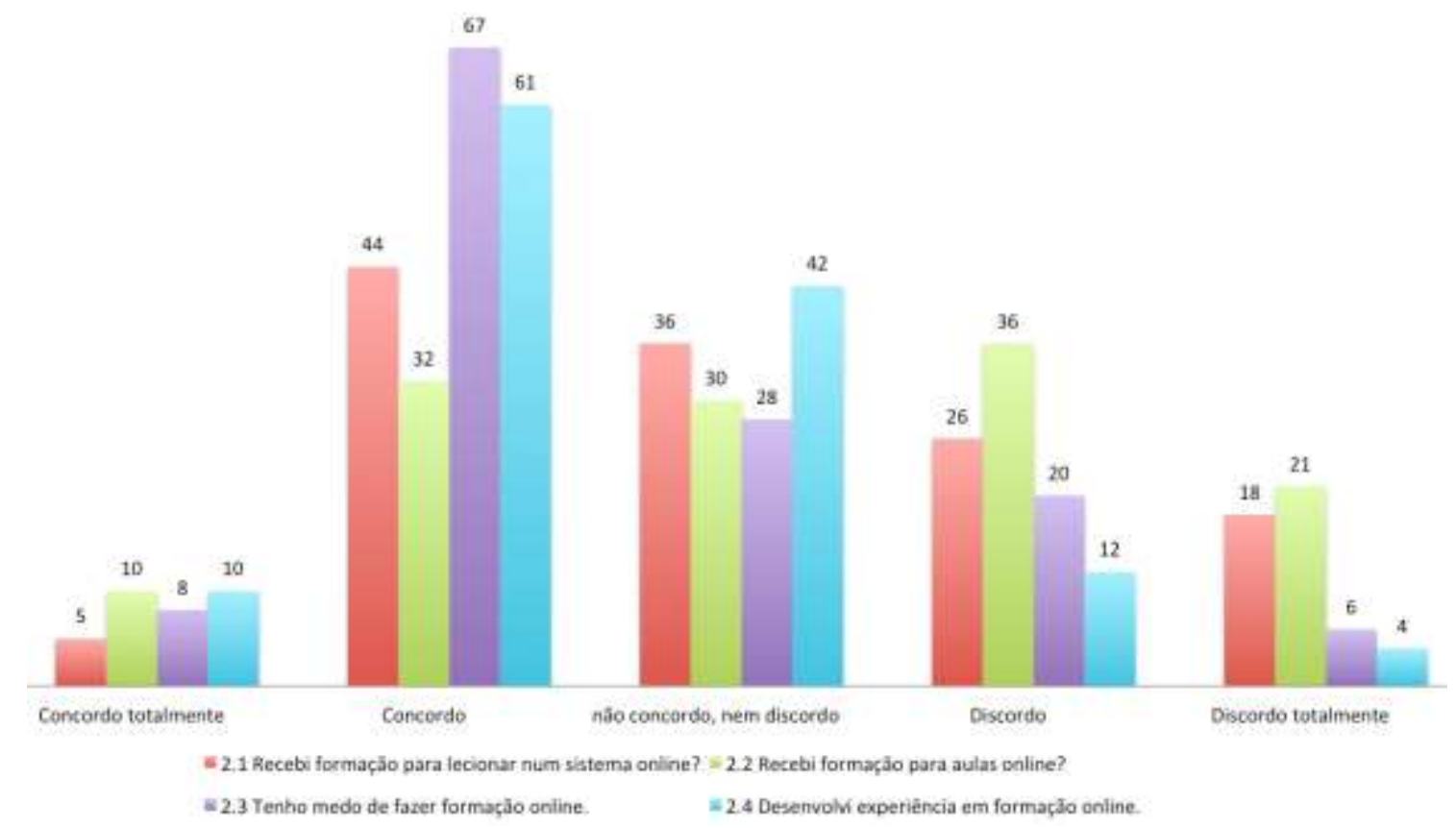

Fonte: Elaborado pelos autores com base na pesquisa realizada (2021).

O gráfico 3 apresenta os resultados dos participantes sobre os problemas que encontraram durante as aulas no ensino-aprendizagem digital.

Os resultados revelaram que a maioria dos formadores lutou contra a instabilidade da internet durante a formação digital, o que gerou uma situação muito estressante e depressiva item 3.1. O estudo também explorou que um número notável defrontou-se com falhas de eletricidade, resultando na perda de tempo não só para os docentes, mas também para os discentes - item 3.2. Da mesma forma, um grande número de participantes relatou que na formação digital não podiam interpretar as reações e expressões não verbais dos estudantes como feedback, o que foi bastante desconcertante. Além disso, um número significativo mencionou alguma dificuldade em ministrar as aulas porque não conseguiam usar a sua linguagem corporal como costumavam fazer na formação presencial - item 3.3.

A comunicação não verbal desempenha um papel fundamental na transmissão e compreensão das mensagens. Os resultados mostraram que os docentes durante as formações digitais não podiam observar os seus estudantes, especialmente quando partilhavam o écran. Os vídeos - câmeras - dos discentes permaneciam desligados durante as aulas remotas e, por esse motivo, os professores não conseguiam receber feedback por meio dos gestos, da comunicação não verbal, das expressões faciais etc. De igual modo, os docentes não podiam utilizar os seus gestos corporais, estando atrás de uma tela, de forma eficiente para melhorar a compreensão dos discentes no decorrer da aprendizagem digital. Bambaeeroo e Shokrpour (2017) documentaram que as atitudes e sentimentos das pessoas podem ser afetados pela linguagem corporal a tal ponto que, em muitos casos, são ainda mais eficazes do que as mensagens verbais. Caldwell et al. (2008) realizaram uma pesquisa sobre o papel das pistas não verbais e afirmaram que as expressões faciais, a linguagem corporal e os gestos dos professores desempenham um papel significativo durante a partilha dos saberes. 
Ainda, uma percentagem notável dos respondentes evidenciou que era muito difícil gerir a classe durante a formação digital - item 3.4 -, pois os desafios persistentes não são apenas uma fonte de estresse e ansiedade constantes, mas contribuem também para a deterioração da saúde mental e da eficácia geral dos docentes.

\section{Gráfico 3 - Problemas enfrentados durante a formação digital ( $N=129)$}

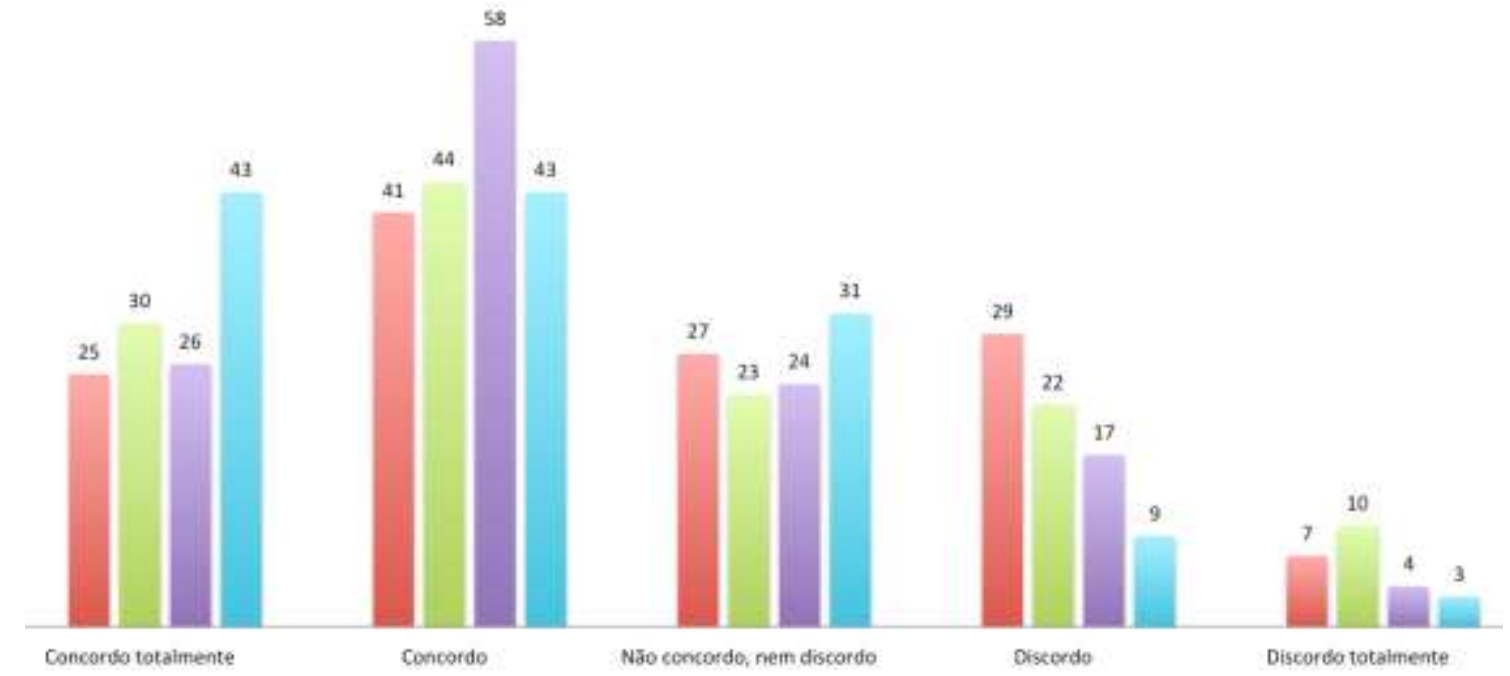

Fonte: Elaborado pelos autores com base na pesquisa realizada (2021).

O gráfico 4 transmite a atitude dos estudantes durante o ensino-aprendizagem digital.

Um grande número de respondentes indicou que a maioria dos estudantes não participou das discussões na formação, negando-se totalmente a falar - item 4.2. Na realização das atividades, muitos alunos recusaram-se a participar tanto das tarefas como das discussões.

Para Mathew e Iloanya (2016), na aprendizagem virtual, não há ou existe pouca interação entre os estudantes devido à falta de contato físico entre eles, o que em consequência representa um obstáculo para o processo de ensino-aprendizagem.

Além disso, outro problema que a grande maioria dos entrevistados relatou foi que durante as aulas remotas, os estudantes saem e voltam sem parar - item 4.5 -, gerando transtorno e desviando a atenção dos professores.

Por fim, uma percentagem perceptível dos participantes alertou que é difícil manter os formandos empenhados e motivados em longas formações - item 4.6.

Houve outro problema sério que surgiu durante as formações digitais: o de manter a capacidade de atenção dos estudantes por duas ou três horas consecutivas, fato bastante desafiador para os professores. Em salas de aula tradicionais, os professores podem envolver a classe em uma variedade de atividades, mas na modalidade digital foi difícil envolver e cativar os discentes por um período prolongado. Svinicki e McKeachie (1999) afirmam que a atenção dos alunos durante as aulas se estende em 10 minutos. Após esse tempo, a capacidade de atenção começa a diminuir. 


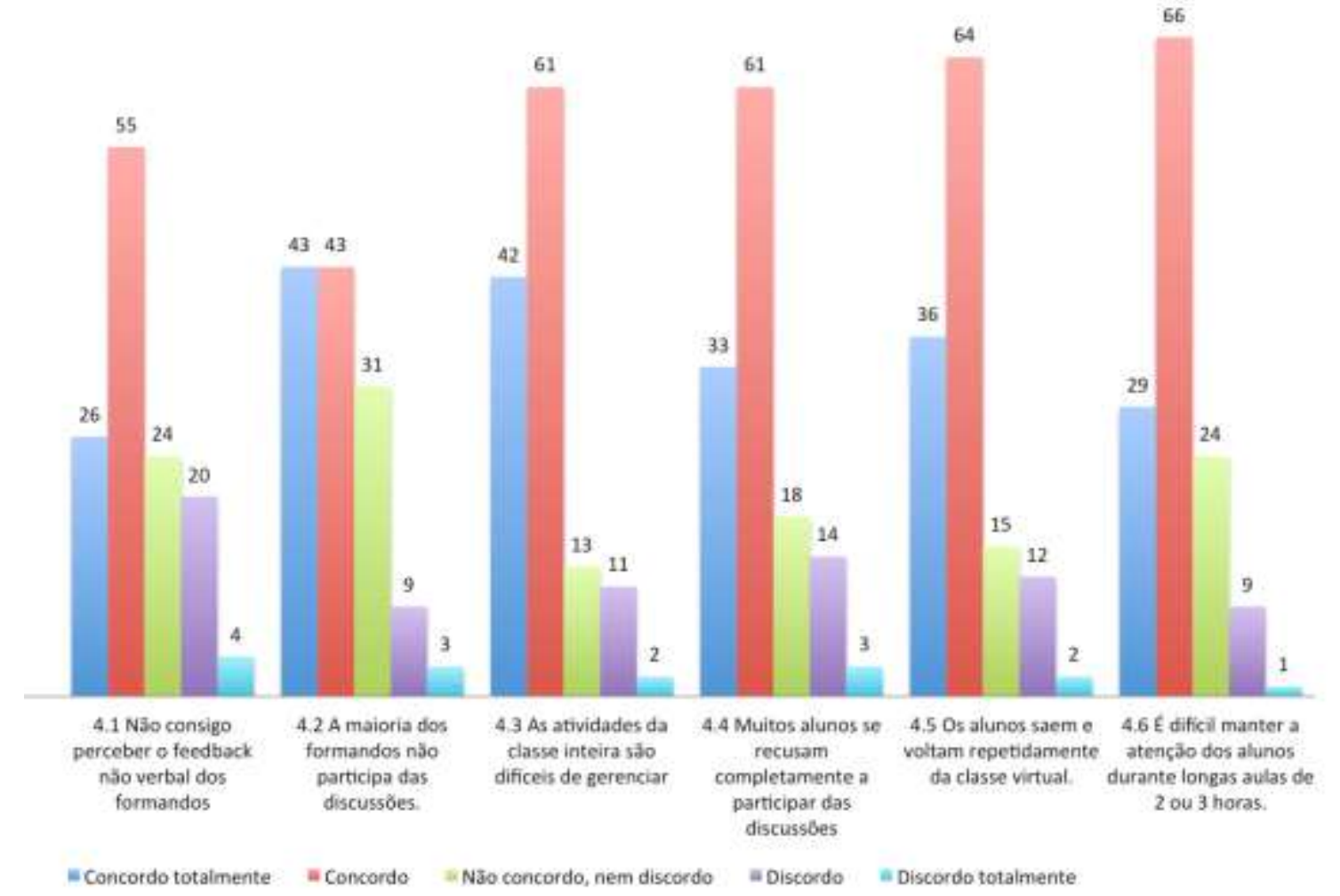

Fonte: Elaborado pelos autores com base na pesquisa realizada (2021).

O gráfico 5 traduz as vicissitudes da avaliação e mostra os resultados sobre os problemas relativos aos métodos avaliativos no ensino-aprendizagem digital. Uma percentagem notável alega que os questionários on-line são mais fáceis de serem realizados - item 5.1; no entanto, a grande maioria afirma que os estudantes podem facilmente pedir ajuda ou mesmo copiar durante a sua realização - item 5.3. Apesar disso, a maior parte dos alunos cumpre com os prazos estipulados - item 5.5 .

As avaliações digitais - tarefas e questionários - permitem mais técnicas de fraude entre os estudantes, o que desafia de forma direta as estratégias de supervisão dos professores. Além disso, as práticas de plágio também levantam a questão da autenticidade e confiabilidade das notas marcadas no sistema de e-learning. Boitshwarelo, Reedy e Billany (2017) evidenciam que o plágio é maior nas avaliações digitais.

Os professores, do mesmo modo, indicaram que o ensino-aprendizagem digital tem um impacto negativo nos resultados gerais dos estudantes. O corolário disso poderia ser uma multiplicidade de fatores, como sinal de internet, falta de eletricidade, falta de experiência e formação etc. Chaudhary, Shahzadi e Mahmood (2019) demonstraram que nos ambientes digitais o sequenciamento de atividades e as questões técnicas aparecem como obstáculos no processo de avaliação. 


\section{Gráfico 5 - Problemas na avaliação na formação digital ( $N$ = 129)}

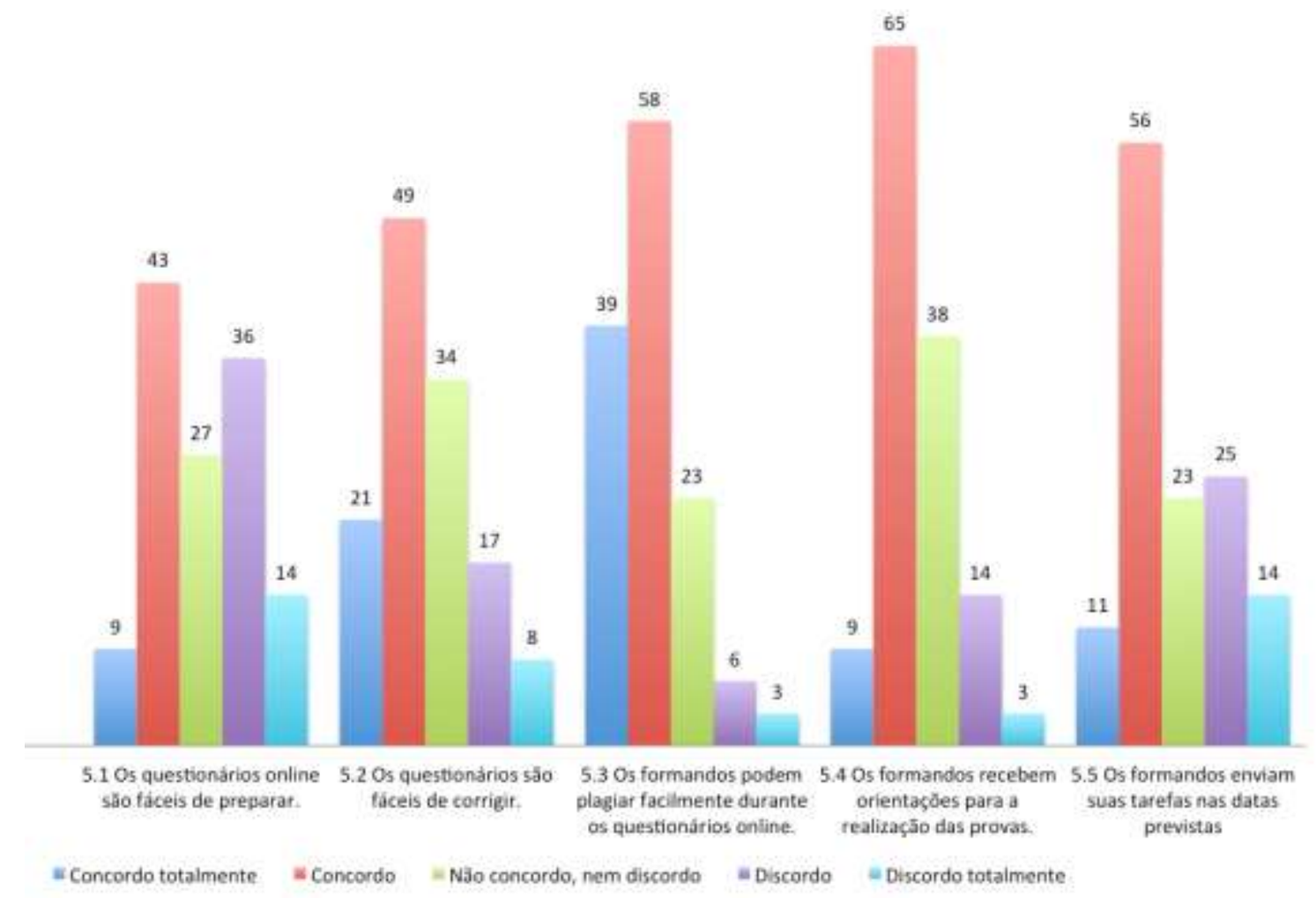

Fonte: Elaborado pelos autores com base na pesquisa realizada (2021).

O gráfico 6 corresponde à visão docente sobre o ensino-aprendizagem digital. Os resultados apontaram que $24,9 \%$ dos participantes concordam que as iniciativas virtuais formações sobre a utilização de plataformas digitais e sobre o ensino na modalidade de elearning - tiveram repercussões positivas; a metade, ou seja, 50,4\% estão indecisos a esse respeito; e 24,9\% mostraram desacordo quanto ao sucesso do sistema de aprendizagem digital durante a pandemia. Ademais, um grande número de participantes relatou que o uso prolongado de auriculares leva a dores incessantes no ouvido - item 6.2. Da mesma forma, uma quantidade notável de docentes indicou que, no sistema de ensino-aprendizagem digital, a falta de interação presencial afeta negativamente a aprendizagem dos discentes. Por fim, a maioria, isto é, 69,8\% afirmaram que a formação digital é entediante e exaustiva quando comparada com o sistema de ensino-formação tradicional - item 6.4.

Os resultados revelaram que as práticas de ensino-aprendizagem digital não são bemsucedidas devido a vários motivos, como: conexão a internet; falta de eletricidade; falta de formação; plágio durante as avaliações; estresse e ansiedade perante uma formação virtual tecnofobia -; etc. Rajab, Ghazal e Alkattan (2020) documentaram resultados semelhantes quanto ao uso demasiado de auriculares por causar deficiência auditiva e infecção no ouvido. O estudo também revelou que o ensino on-line é exigente e demorado, uma vez que os docentes permanecem de maneira contínua envolvidos na atualização do material dos cursos na modalidade de e-learning. Grabinski et al. (2020) apontam que a lecionação de aulas virtuais implica um grande investimento de tempo - diferente das aulas presenciais - e exige uma maior disponibilidade dos professores durante os sete dias da semana. Englund, Olofsson e Price (2017) 
corroboram ao sugerir que o ensino-aprendizagem digital exige dos professores o domínio de uma variedade de ferramentas, sistemas e softwares.

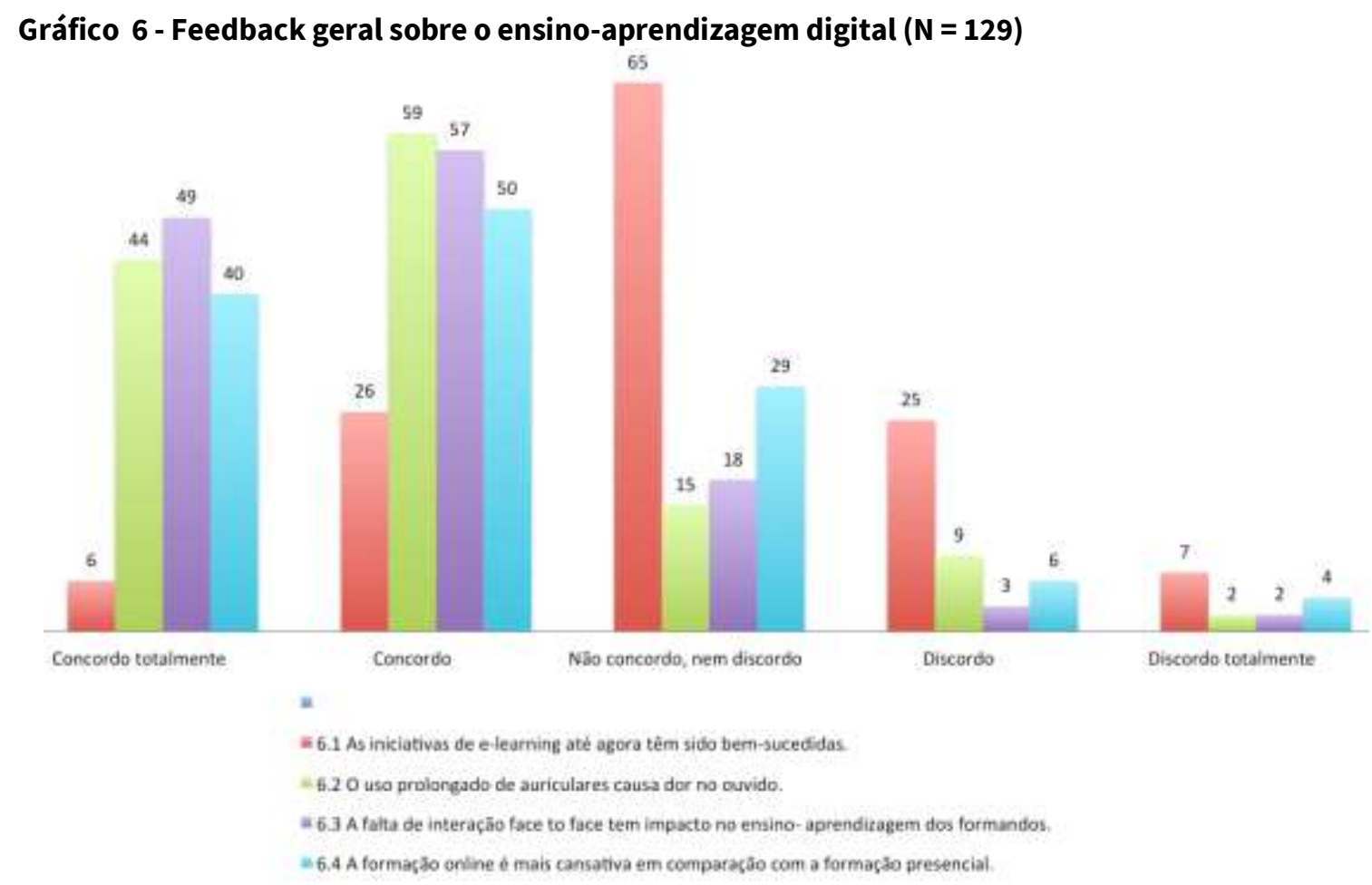

Fonte: Elaborado pelos autores com base na pesquisa realizada (2021).

\section{CONSIDERAÇÕES FINAIS}

As conclusões gerais do estudo salientaram diversos desafios que os docentes enfrentaram no sistema de educação virtual. A crescente demanda no contexto atual da pandemia de COVID19 conjugada com uma tecnologia digital em constante mudança; a falta de recursos financeiros; uma formação adequada para cursos virtuais; mais gastos econômicos devido ao uso extensivo da internet; conexão fraca com a internet; plágio em avaliações on-line; e aumento da carga de trabalho representaram grandes desafios para professores e educadores. Os problemas iniciais já eram esperados devido à obrigatoriedade das aulas on-line. Além dos impedimentos mencionados acima, este tempo sem precedentes também ofereceu algumas oportunidades para os docentes reinventarem e reconstruírem seus papéis a fim de garantir um fluxo suave do processo de ensino-aprendizagem.

Para cumprir os requisitos da era pós-pandemia, os professores devem desempenhar um papel significativo na reformulação do sistema on-line existente. Com base no estudo, sugere-se as seguintes recomendações: os professores devem conceber atividades interessantes e diversificadas para chamar e reter a atenção dos discentes, envolvendo-os em atividades de pensamento crítico e resolução de problemas; os métodos de avaliação devem ser cuidadosamente planeados e implementados para combater a fraude; os docentes devem concentrar-se em plataformas de ensino digital para tornar o seu ensino on-line mais eficaz. 
Nesse sentido, devem receber formação e orientações sobre como usar diferentes plataformas para um ensino efetivo na referida modalidade; o ponto de vista dos professores deve ser levado em conta, pois irá nortear o futuro da Educação, tanto nacional como local.

Esse período de provações salientou fortemente a atitude dos professores em apoiar e educar os jovens e os adultos num contexto de crise nunca antes vivido. 0 ensino-aprendizagem não foi suspenso e, apesar das incertezas, da confusão e dos obstáculos, o corpo docente superou o desafio de maneira brilhante.

O confinamento, as medidas de distanciamento e a desordem provocada pelo digital, tanto na comunicação pessoal como profissional, evidenciou que o ser humano é um ser de relações. O ensino-aprendizagem digital tem o seu lugar, mas não pode ocupar o espaço todo: deve responder a necessidades reais de acessibilidade e a critérios ligados às necessidades escolares e pedagógicas.

\section{REFERÊNCIAS}

ABERNATHY, D. F.; THORNBURG, A. W. Theory and application in the design and delivery of engaging online courses: Four key principles that drive student and instructor engagement and success. In: THORNBURG, A. W.; ABERNATHY, D. F.; CEGLIE, R. J. Handbook of research on developing engaging online courses. Hershey, PA: IGI Global, 2020.

ASSAREH, A.; BIDOKHT, M. H. Barriers to e-teaching and e-learning. Procedia Computer Science, v. 3, p. 791-795, 2011. Disponível em:

https://www.sciencedirect.com/science/article/pii/S1877050910005041?via\%3Dihub. Acesso em: 26 fev. 2021.

BAMBAEEROO, F.; SHOKRPOUR, N. The impact of the teachers' non-verbal communication on success in Teaching. Journal of Advances in Medical Education \& Professionalism, v. 5, n. 2, 2017. Disponível em: https://www.ncbi.nlm.nih.gov/pmc/articles/PMC5346168/. Acesso em: 26 fev. 2021.

BAXTER, J.; CALLAGHAN, G.; MCAVOY, J. Introduction to chapters: Creativity and critique in online teaching and learning: Innovations in online pedagogy. In: Creativity and critique in online learning. Cham, Switzerland: Palgrave Macmillan, 2018.

BOITSHWARELO, B.; REEDY, A. K.; BILLANY, T. Envisioning the use of online tests in assessing twenty-first century learning: a literature review. Research and Practice in Technology Enhanced Learning, v. 12, n. 16, Aug. 2017. Disponível em: https://telrp.springeropen.com/articles/10.1186/s41039-017-0055-7. Acesso em: 26 fev. 2021.

BOZKURT, A.; SHARMA, R. C. Emergency remote teaching in a time of global crisis due to Corona Virus. Asian Journal of Distance Education, v. 15, n. 1, p. i-vi, 2020. Disponível em: https://zenodo.org/record/3778083\#.YOYOOuhKjDc. Acesso em: 26 fev. 2021.

CHAUDHARY, F. R.; SHAHZADI, I.; MAHMOOD, A. Comparative study of satisfaction and problems of face to face and online mode of learners. International Journal of Distance Education and E-Learning, v. 4, n. 1, 2019. Disponível em: http://irigs.iiu.edu.pk:64447/ojs/index.php/IJDEEL/article/view/477. Acesso em: 26 fev. 2021. 
CALDWELL, D. et al. A framework for student engagement: Strategies for faculty teaching online. In: KYEIBLANKSON, L.; NTULI, E.; BLANKSON, J. Handbook of research on creating meaningful experiences in online courses. Hershey, PA: IGI Global, 2020.

DEI, D. G. J.; Assessing quality assurance practices in institutions of higher learnings. International Journal of Learning, Teaching and Educational Research, v. 18, n. 12, p. 30-45, 2019. . Disponível em: https://www.ijlter.org/index.php/ijlter/article/view/1676. Acesso em: 26 fev. 2021.

DHAWAN, S. Online-learning: A Panacea in the Time of COVID-19 Crisis. Journal of Educational Technology System, v. 49, n. 1, 2020. Disponível em: https://journals.sagepub.com/doi/10.1177/0047239520934018. Acesso em: 26 fev. 2021.

ENGLUND, C.; OLOFSSON, A. D.; PRICE, L. Teaching with technology in higher education: Understanding conceptual change and development in practice. Higher Education Research \& Development, v. 36, n. 1, p. 73-87, 2017. Disponível em: https://uobrep.openrepository.com/handle/10547/622389. Acesso em: 26 fev. 2021.

GIL, A. C. Como Elaborar Projetos de Pesquisa. 6. ed. São Paulo: Atlas, 2019.

GRABINSKI, K. et al. Embedding E-Learning in Accounting Modules: The Educators' Perspective. Education Sciences, v. 10, n. 4, 2020. Disponível em: https://www.mdpi.com/2227-7102/10/4/97. Acesso em: 26 fev. 2021.

ISLAM, N.; BEER, M.; SLACK, F. E-Learning Challenges Faced by Academics in Higher Education: A Literature Review. Journal of Education and Training Studies, v. 3, n. 5, p. 102-112, 2015. Disponível em: https://files.eric.ed.gov/fulltext/EJ1069559.pdf. Acesso em: 26 fev. 2021.

LEÃO, L. M. Metodologia do Estudo e Pesquisa: facilitando a vida dos estudantes, professores e pesquisadores. Petrópolis: Vozes, 2017.

MARCONI, M. A.; LAKATOS, E. M. Fundamentos de Metodologia Científica. 5. ed. São Paulo: Atlas, 2003.

MATHEW, I. R.; ILOANYA, J. E. Open and Distance-learning: Benefits and Challenges of Technology Usage for Online Teaching and Learning in Africa. In: PAN-COMMONWEALTH FORUM 8 (PCF8), Africa, Commonwealth of Learning (COL) and Open University Malaysia (OUM), 2016. Disponivel em: http://oasis.col.org/handle/11599/2543. Acesso em: 26 fev. 2021.

MAZZARDO, M. D.; NOBRE, A.; MALLMANN, E. M. Competências Digitais dos Professores para Produção de Recursos Educacionais Abertos (REA). RE@D: Revista de Educação a Distância e Elearning, v. 2, n. 1, 2019. Disponível em: https://revistas.rcaap.pt/index.php/lead_read/article/view/22057. Acesso em: 26 fev. 2021.

SVINICKI, M.; MCKEACHIE, W. J. McKeachie's Teaching Tips: Strategies, Research, and Theory for College and University Teachers. 10. ed. Belmont, CA: D C Heath \& Co, 1999.

MCLEOD, S. Questionnaire: definition, examples, design and types. 2018. Disponível em: https://www.simplypsychology.org/questionnaires.html. Acesso em: 26 fev. 2021.

MURPHY, M. P. A. COVID-19 and emergency eLearning: Consequences of the securitization of higher education for post-pandemic pedagogy. Contemporary Security Policy, v. 49, n. 3, 2020. Disponível em: https://www.tandfonline.com/doi/full/10.1080/13523260.2020.1761749. Acesso em: 26 fev. 2021. 
NOBRE, A. M. F. et al. Tabla DK eLearning: optimización de la práctica docente en un ambiente online, RED. Revista de Educación a Distancia (RED), v. 19, n. 59, 2019. Disponível em:

https://revistas.um.es/red/article/view/361121. Acesso em: 26 fev. 2021.

NOBRE, A. Educational practices resulting from Digital Intelligence. In: PANCONESI, G.; GUIDA, M.

Handbook of Research on Teaching With Virtual Environments and AI. Hershey, PA: IGI Global, 2021.

NOBRE, A. The Pedagogy That Makes the Students Act Collaboratively and Open Educational Practices. In: TADLAOUI, M. A.; KHALDI, M. Personalization and Collaboration in Adaptive e-learning. Hershey, PA: IGI Global, 2020.

NOBRE, A.; MOURAZ, A. Reflexões sobre os efeitos da pandemia na aprendizagem digital. Dialogia, São Paulo, n. 36, p. 367-381, set./dez. 2020. Disponível em: https://doi.org/10.5585/dialogia.n36.18722. Acesso em: 26 fev. 2021.

RAJAB, M. H.; GHAZAL, A. M.; ALKATTAN, K. Challenges to Online Medical Education During the COVID-19 Pandemic. Cureus, v. 12, n. 7, e8966, Jul. 2020. Disponível em: https://www.cureus.com/articles/30131challenges-to-online-medical-education-during-the-covid-19-pandemic. Acesso em: 26 fev. 2021.

RODDY, C. et al. Applying Best Practice Online-learning, Teaching, and Support to Intensive Online Environments: An Integrative Review. Frontiers in Education, 2017. Disponível em: https://www.frontiersin.org/articles/10.3389/feduc.2017.00059/full. Acesso em: 26 fev. 2021.

SIDDIQUEI, N. L.; KHALID, R. According to the E-Learning Policy (2007-2010) of University of Liverpool, "Elearning is learning which is enhanced, supported or assessed by the use of electronic media. E-learning may involve the use of new or established technology and/or the creation. International Journal of Law, Humanities \& Social Science, p. 20-35, 2017.

SUN, A. Q.; CHEN, X. Online Education and Its Effective Practice: A Research Review. Journal of Information Technology Education: Research, v. 15, p. 157-190, 2016. Disponível em: http://www.jite.org/documents/Vol15/JITEv15ResearchP157-190Sun2138.pdf. Acesso em: 26 fev. 2021.

TERESEVICIENE, M. et al. Are universities ready to recognize open online learning?. International Education Studies, v. 13, n. 2, p. 21-32, 2020. Disponível em: https://www.researchgate.net/publication/338916708_Are_Universities_Ready_to_Recognize_Open_Onli ne_Learning. Acesso em: 26 fev. 2021.

YIN, R. K. Case study research: design and methods (applied social research methods). Thousand Oaks, CA: Sage Publications, 2009. 